\section{EMBnet, the Global Bioinformatics Network: a report on the workshop and 26th AGM, Lyon, May 2014}

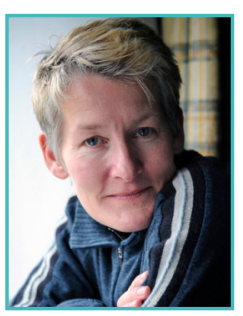

\section{Teresa K. Attwood}

University of Manchester, Manchester, United Kingdom

Received 26 July 2014; Published 24 September 2014

Attwood TK (2014) EMBnet.journal 20, e786. http: !t/dx.doị. org/10,14806/ej.20.0.786

\section{Introduction}

EMBnet's 2014 Annual General Meeting (AGM) and associated events were hosted in Lyon (FR), from 26 to 30 May. This $26^{\text {th }}$ formal meeting of EMBnet provided an opportunity both to partner with the Bioinformatics for Environmental Genomics workshop of the Pluridisciplinary Thematic Network in Environmental Genomics, and to review progress since the silver anniversary meeting in Valencia (ES) last year.

The occasion of the AGM included several events: i) a one-day EMBnet tutorial at the Pôle Rhône-Alpes de Bioinformatique (PRABI) on the Doua campus of the University of Lyon 1, entitled From NGS data through the third dimension towards new agrochemicals and drugs - this included sessions on RNA-seq analysis, tutored by Vincent Lacroix and Vincent Navratil; the Hope protein structure-function analysis suite, led by Gert Vriend; and the STING platform, demonstrated by Goran Neshich; ii) the two-day Bioinformatics for Environmental Genomics workshop, which took place in the École Supérieure de Chimie Physique Électronique de Lyon, with 200 participants, also on the Doua campus; iii) a one-day EMBnet workshop held (partly) in Lyon's Hôtel de la Cité; and finally, iv) the traditional business meeting, also held in the Hôtel de la Cité.

The EMBnet workshop got off to an interesting start. A major fault with the hotel's fire-alarms forced us to abandon the meeting room and to transfer to the lobby/bar area to begin the busi- ness of the day (in doing so, we had to turn the agenda upside-down, beginning with roundtable discussions and leaving formal reports for later); after mid-morning coffee, we transferred to a meeting room in an adjacent hotel, where we continued with the Executive Board (EB) and Committee Chair reports; we then returned to the Hôtel de la Cité to pick up the pieces of the now-dishevelled agenda after lunch! Despite the disruptions, we nevertheless managed to have some very constructive discussions, with concrete outcomes for the future.

The past year has been another busy one, much of our time being devoted to supporting our allied research projects, initiatives and affiliates (SeqAhead, AllBio, GOBLET, ISCB), alongside the routine work of running the Stichting. In this report, we begin by reviewing some of the year's principal efforts to build on these initiatives and affiliations, we make a critical analysis of EMBnet's current status, and we conclude with a summary of the workshop's main conclusions.

\section{Activities and achievements of the last year}

During the last year, our efforts have been concentrated in three main areas: education and training; allied research projects; and outreach/ dissemination.

\section{Education and training}

Members of EMBnet have organised, participated in and/or presented EMBnet at, a range of bioinformatics courses and summer schools. These include, but are not limited to, the EBI-Wellcome Trust Bioinformatics Summer School in Hinxton, UK (June 2013); the NGS bioinformatics course at KEMRI-Wellcome Trust in Kilifi, KE (August 2013); and, of course, the AGM tutorial (May 2014).

During the 2013 EMBnet workshop, we had agreed to devote more time to producing QuickGuides. Accordingly, two new guides were produced, one on amino acids, the other on the semi-empirical quantum mechanics software package, MOPAC, both of which have been published (see Figure 1); several others are currently in production - please visit the website for the latest information on all other published QuickGuides'.

Overall, EMBnet's training strategy has been dominated by our leadership of the Global

1 www.embnet.org/embnet-quickguides 

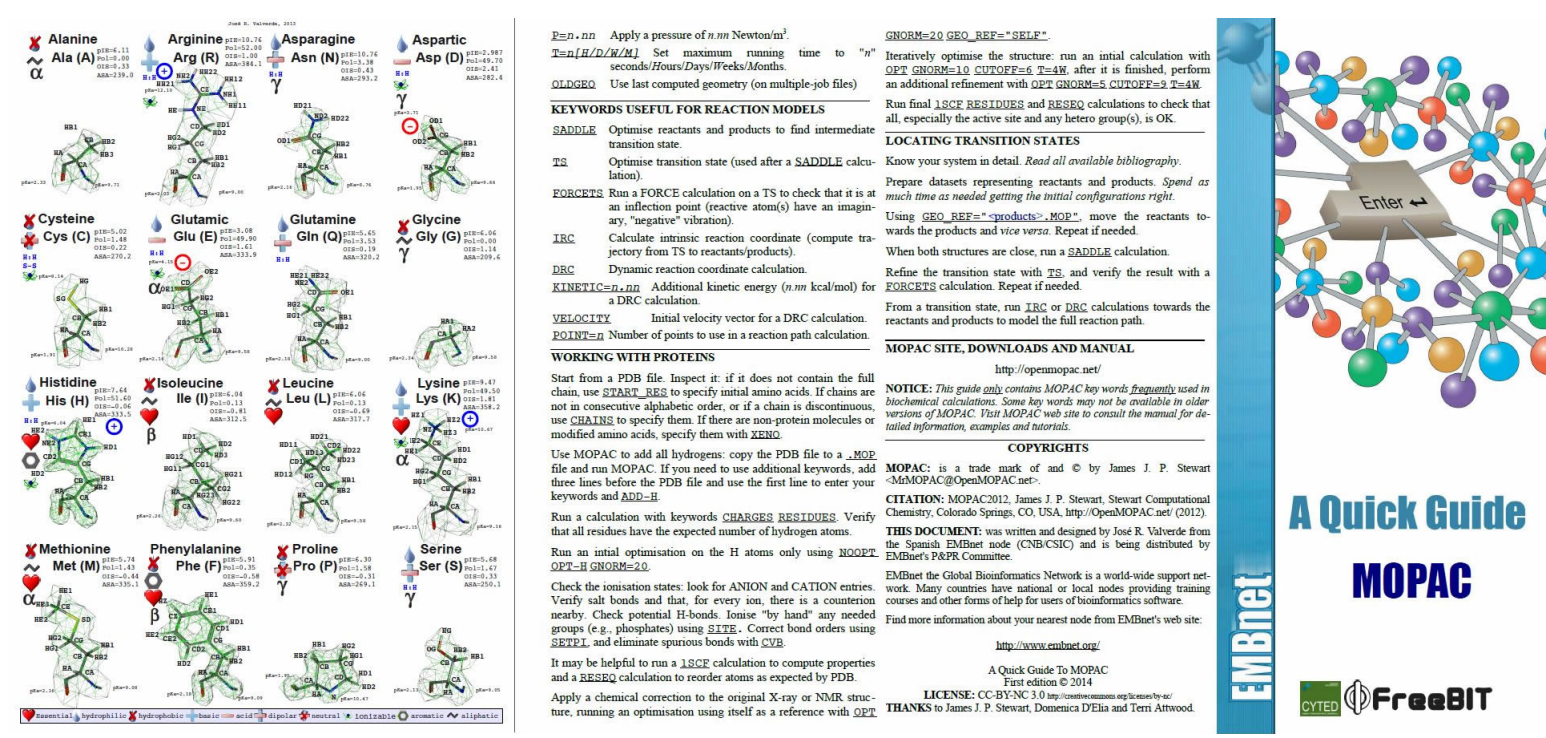

Figure 1. Illustration of panels from the Amino Acid and MOPAC QuickGuides.

Organisation for Bioinformatics Learning, Education and Training (GOBLET $\left.{ }^{2}\right)$. GOBLET, which, at the time of writing, has $\sim 30$ members, held its first formal AGM at The Genome Analysis Centre (TGAC), Norwich (UK) in November 2013, a year after its kick-off meeting in Amsterdam (NL). This event took place the day after a pan-European bioinformatics training strategy meeting (also at TGAC): this had been organised largely to be able to discuss how GOBLET and ELIXIR ${ }^{3}$ could work together in mutually supportive ways to best serve their communities in future, to build on each other's strengths and obviate unnecessary duplication of effort.
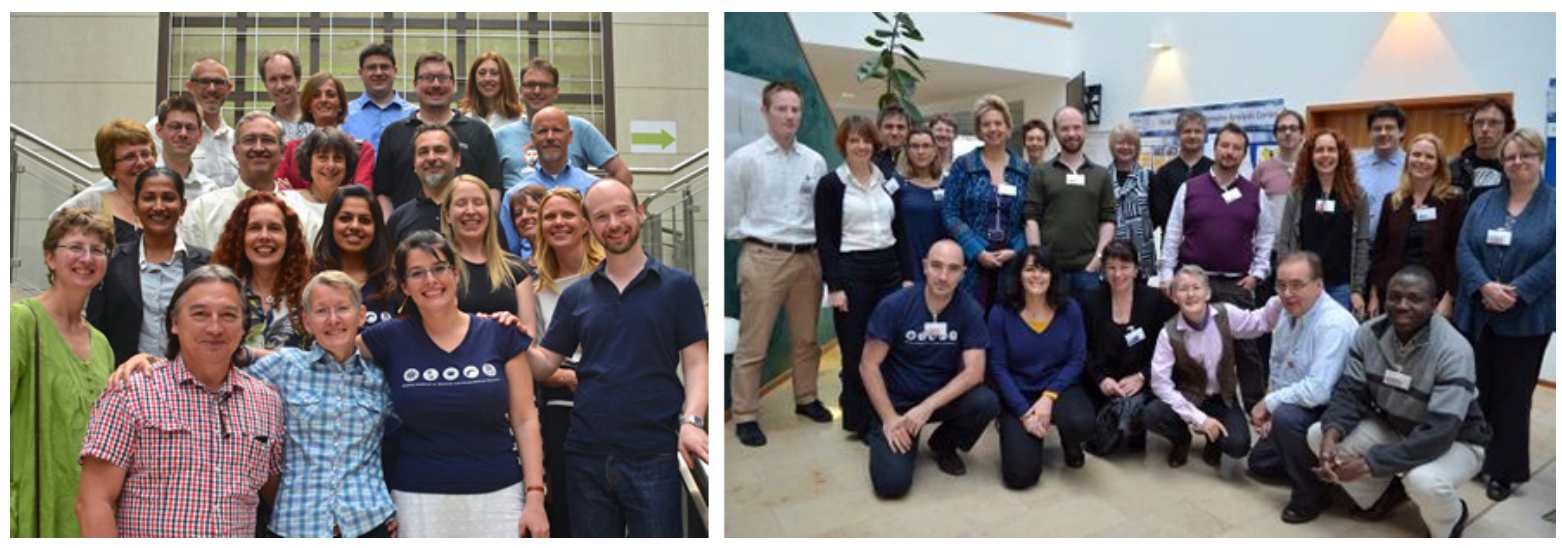

Figure 2. From left to right: participants of the interim GOBLET meeting held in Berlin (July2013), and of the first formal GOBLET AGM held at TGAC, Norwich (November 2013).

2 www.mygoblet.org

3 www.elixir-europe.org

page 2 of 8

(not for indexing) 
Conesa (on multidisciplinary, multi-institutional $\mathrm{PhD}$ programmes), from Anupama Jigisha (on the ISCB Student Council intern initiative), and from Niklas Blomberg (on how ELIXIR will safeguard life science research in Europe); and iv) preparing a GOBLET feature article for the ISCB newsletter.

\section{Allied research projects}

During the year, a significant amount of time was also devoted to working with our allied EU-funded projects. Specifically, members of EMBnet helped organise and/or attended a range of AllBio events" ${ }^{4}$ these included a number of 'hackathons' (August 2013, Nijmegen, NL; September 2013, Amsterdam, NL; October 2013, Uppsala, SE; November 2013, Alnarp, SE), an RNA-seq data analysis workshop (January 2014, Espoo, FI), the AllBio/EMBRACE metagenomics interoperability workshop (April 2014, Amsterdam, NL), and the AllBio AGM (September 2013, London, UK).

Within SeqAhead ${ }^{5}$, members of EMBnet were involved in events covering a range of problems in NGS data analysis: these included the NGS data and the Variation Calling Challenge (May 2013, Udine, IT); Hadoop and NGS data processing hackathon III (June 2013, Pula, IT); workshops on the Future demands and challenges in ICT and bioinformatics tools for NGS (June 2013, Pula, IT), NGS methods for identification of mutations and large structural variants (March 2014, Lausanne, $\mathrm{CH}$ ) and Assessment of training methods in NGS data analysis (March 2014, Oeiras, PT); and the NGS data after the Gold rush workshop and Management Committee Meeting (May 2014, Norwich, UK) - see Figure 3.

\section{Outreach/dissemination}

Throughout the year, we have described these and other activities in the monthly EMBnet.digest and in EMBnet.journal. For example, we made a special report on EMBnet's silver anniversary AGM in the May 2013 digest, we provided a round-up of the year's activities in the December issue, and we provided a report on our work with GOBLET, and invited EMBnet to participate in a GOBLET survey in February's digest. The most notable change for the digest has been a new, much simpler look-and-feel, starting from the January 2014 issue, as illustrated in Figure 4.

For the Journal, the most notable change has been a move to an instant access model, in which articles are published as soon as peerreview and layout have been completed - articles will henceforth be collated into volumes only once a year, commencing with volume 20 .

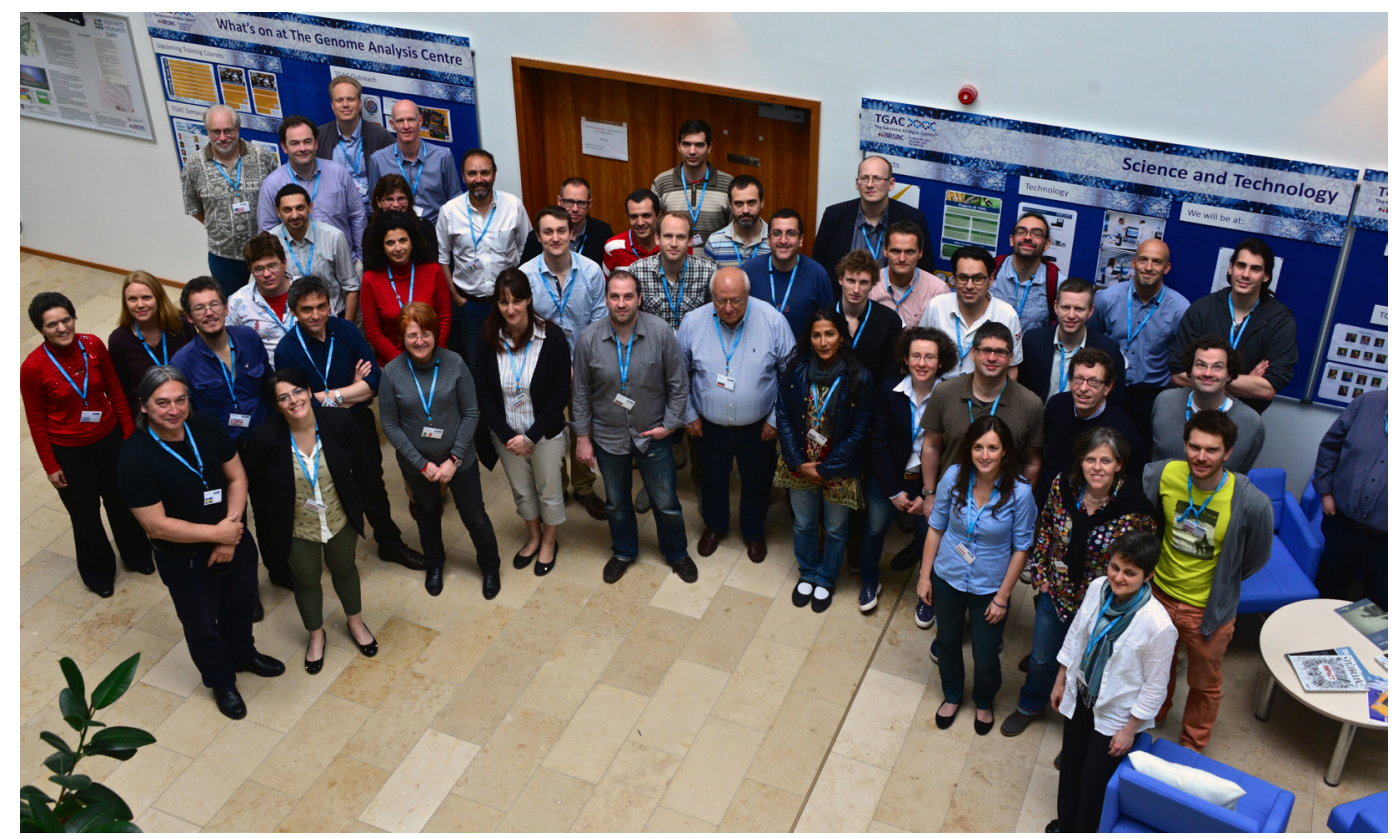

Figure 3. Participants of the SegAhead NGS data after the Gold rush workshop held at TGAC, UK (May 2014).

4 www.allbioinformatics.eu/doku.php?id=public:events

5 www.segahead.eu 

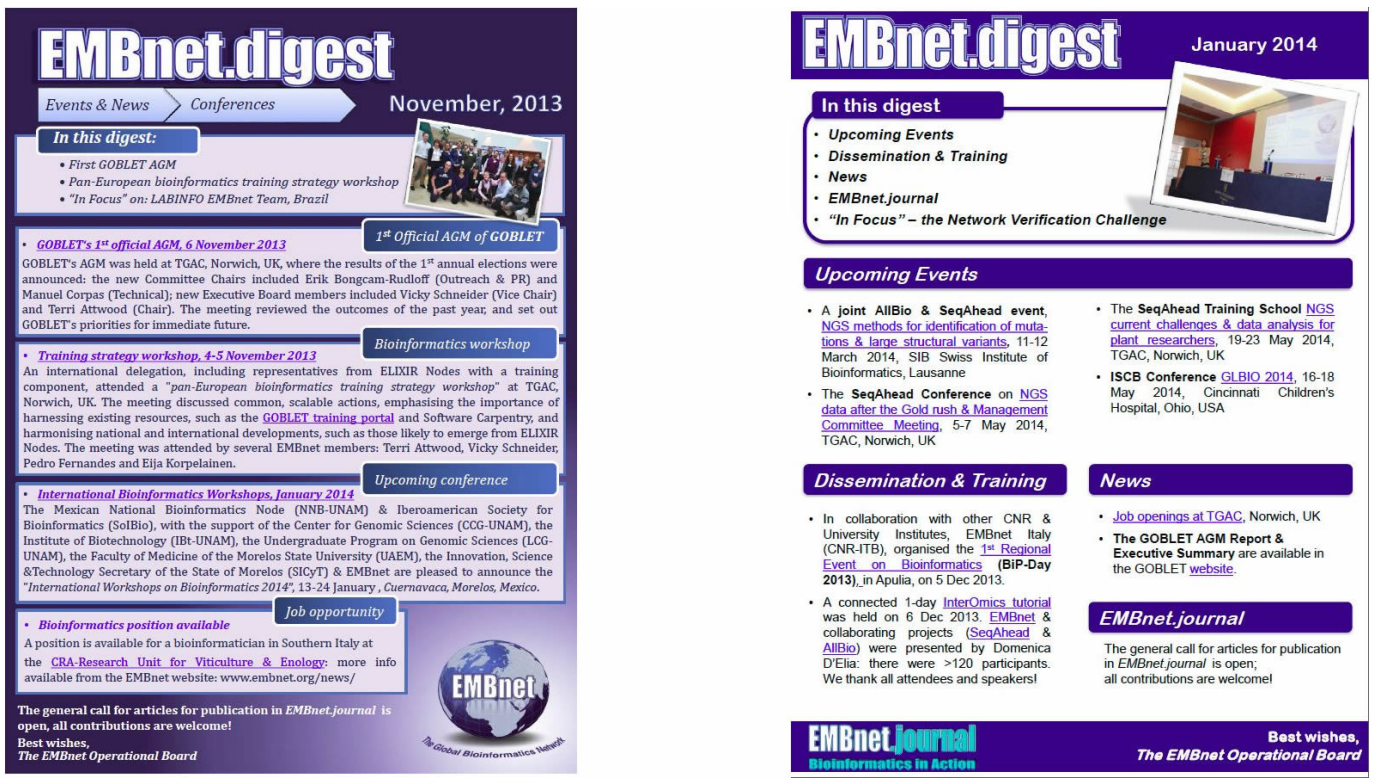

Figure 4. From left to right: screen-grabs illustrating the old- and new-look EMBnet.digest, respectively.

During 2013, as illustrated in Figure 5, the bulk of the journal work involved preparation of volume 19(1) (which included reports from the EMBnet 2013 AGM, held 17-18 May in Valencia, ES) and proceedings of the The Next NGS Challenge Conference: Data Processing and Integration conference, held 14-16 May in Valencia, and of the NETTAB 2013 workshop on Semantic, Social and Mobile Applications for Bioinformatics and Biomedical Laboratories, held 16-18 October in the Venice Lido (IT).

\section{Structural changes}

Following the successful ratification of the new statutes, which became legally binding in April 2013, we have been formally able to accept
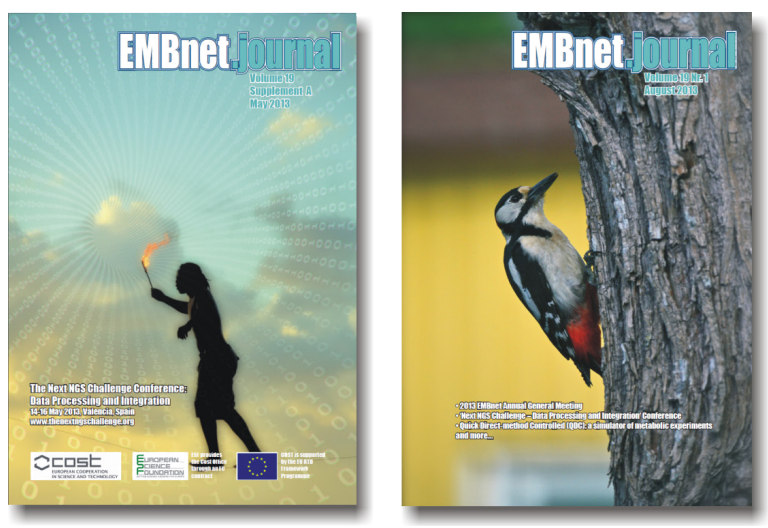

individual members, a facility made possible by implementation of the online fee-payment module; accordingly, we were able to welcome a new individual member to the AGM, Axel Thieffry, who gave an entertaining talk by way of introduction. The new statutes also ushered in changes to the internal structure of the organisation. In particular, Committee Chairs now have the flexibility to convene their own working groups and task-forces, without having to proceed via cumbersome election processes.

EMBnet's 2014 workshop and AGM provided opportunities to critically assess how some of these changes have been working in practice. The events also offered a chance to discuss ways of building on some of these initiatives, of kick-
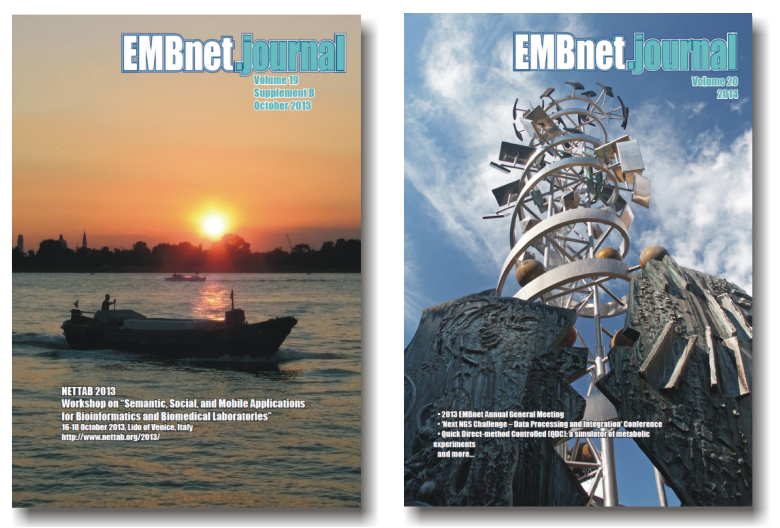

Figure 5. Covers of the principal EMBnet.journal publications from the last and current year. 
starting new projects and of seeking joint funding opportunities to support them.

\section{A critical review}

Clearly, a lot has been done during the last year, but it's also evident that this is not a time to relax - with greater engagement of EMBnet members, with more coherent leadership of the Committees and more inclusive approaches by the Executive Board (EB), EMBnet could have achieved more, and could achieve a lot more in future.

A brief review of the Committees suggested that only one of these was highly active (the Publicity and Public Relations Project Committee (P\&PR PC)), but that this was largely the work of one individual - it was therefore strongly recommended to delegate more of the work of this Committee to others (and EMBnet members are strongly encouraged to lend their support). At the other extreme, the Education and Training Project Committee (E\&T PC) seemed largely dormant, with no Committee members being indicated on the website, and hence presumably no meetings having taken place - it was therefore strongly recommended to revitalise this Committee, to recruit members and list them on the website, and to deliver some concrete results during the coming year. The Technical Management Committee (TM PC) sat somewhere in the middle in terms of activity, but lacked coherence (e.g., website maintenance was largely undertaken outside the Committee, and was hence not included as part of the annual report) - it was therefore strongly recommended to revisit the structure of this Committee and to better define its role and responsibilities. Finally, it was felt that the EB could provide more guidance to the Committee Chairs via the Operational Board Meetings, but importantly also that it should run more Virtual General Meetings (VGMs) with the full EMBnet constituency. Although these have been dogged by technical problems in the past, Adobe Connect seems to work reasonably well. It was therefore recommended to re-establish regular VGMs to reach out to, to better engage with and to better inform EMBnet members of the work of the Committees and of the EB.

Overall, then, it was agreed that the Committee Chairs and the EB should review their structure and membership; that they should begin seriously to delegate tasks and/or to recruit new members, as appropriate; that they should update the website with new information; and, most importantly of all, that they should meet on a regular basis in order to be able to deliver, and ultimately report on, real, demonstrable, tangible outcomes.

Of relevance to this critical review (albeit discussed during the AGM rather than the workshop), was an analysis of the EMBnet tutorial. A number of concrete conclusions were drawn from the experience of running this event; if properly implemented, it was felt that these could improve the professionalism and value of future tutorials. Specifically, it was agreed that the E\&T PC should lead the development of a core tutorial programme, together with a set of ground rules for running and hosting these events: these would include consideration of a range of aspects, such as the capacity of the room (e.g., up to a recommended maximum of $\sim 30$ participants); availability of desktops (or laptops, if participants bring their own); trouble-shooting the local infrastructure in advance; inviting guest speakers (with a budget set aside for this); placing the tutorial closer to the AGM, in order to provide better continuity between these events; and so on (it was noted that many of the suggestions made here had already been published in recent years by the Bioinformatics Training Network - e.g., see Schneider et al., 2010; Via et al., 2011; Via et al., 2013 - whose recommendations should ideally form the bedrock of future tutorial organisation). Ultimately, it was suggested that EMBnet should aim to develop an expanded tutorial, up to two days in length, and to apply a small fee so that the event covers its costs, or better, brings some small level of income back into EMBnet.

\section{New initiatives}

Perennial challenges for EMBnet, as with pretty much all professional networks and societies, are how to engage with existing members and how to attract new ones. Key to addressing these issues are the need to present both a range of active projects with which, given the opportunity, members could become involved, and a tangible set of benefits associated with their involvement. Discussion of these points, and especially how to expand EMBnet's membership, focused once again on potential target groups. One of these is the Linkedln EMBnet group, members of which could potentially be encouraged to join 
EMBnet. However, it was clear that appropriate incentives would need to be in place if we were to be successful in stimulating greater interest in and engagement with EMBnet's work. To this end, two new proposals were outlined: i) EMBnet Fellowships; ii) EMBnet Awards.

\section{EMBnet Fellowship Programme}

The proposal here was for EMBnet to inaugurate a new 'Fellowship Programme' to fund researchers in exchange for their expertise and support. Broadly speaking, the idea of the Programme would be to encourage Fellows both to build on EMBnet's work and to develop their own interests in areas such as bioinformatics resource development, policy development, capacity building and bioinformatics training.

The idea is that two prestigious 18-month Fellowships would be awarded during the next year, in which successful applicants would be allocated $€ 2,000$ to support activities that are mutually beneficial for the Fellow and for EMBnet. The funding is intended to be flexible in order to encompass a range of activities: to develop bioinformatics tools and resources, to conduct surveys, to run workshops, to host training events, and so on. In the first call, priority would be given to proposals that specifically identify collaborative projects with EMBnet's Executive Board, with its Committees or with its publications (EMBnet. journal, EMBnet.digest, EMBnet QuickGuides).

Again, for maximum flexibility, applicants would be eligible from all ages and career stages (from students, to early stage researchers and principal investigators). Although the Programme would not be open to Organisational Members (Node Managers), Individual Members would be strongly encouraged to apply. At the end of the Fellowship, successful candidates would be invited to present their work during the next AGM, to submit a report or article for publication in EMBnet.journal, and an executive summary both for announcement in the 'In Focus' section of EMBnet.digest and for publication on the website.

It was generally agreed that this would be a good initiative to pursue. A range of new Web pages would need to be established (to promote the call for proposals, to celebrate the winners and to promote their work), a new Fellowship email list would need to be set up, and a review panel would need to be instantiated in order to be able to launch the initiative. It was agreed that the EB, with support from the TMPC and P\&PR PC, should progress this as soon as possible.

\section{EMBnet Service Awards}

In addition to encouraging new members to become involved in its work, EMBnet would also like to reward existing members for their dedication both to helping EMBnet's growth and development, and to assuring its continued position as an important global bioinformatics network. It was therefore proposed that an EMBnet Service Award could be given to an EMBnet member (Organisational or Individual) who had contributed significant effort to the success of EMBnet. The activities for receiving this award could be as varied as publishing an important work that mentions EMBnet, running an outstanding education/ training event under EMBnet's patronage, developing new EMBnet-branded educational materials (e.g., QuickGuides, tutorials) or tools, supporting/enhancing EMBnet's website or publications (EMBnet.journal, EMBnet.digest, etc.), bringing in new members or creating effective initiatives to help do so, establishing new synergies or collaborations, and so on.

The procedure would be to open an annual call to EMBnet members to nominate recipients of the award, with a short statement describing the nominee's contribution and hence why the award was deserved. In line with EMBnet's normal voting procedures, a majority of votes would be required for the award to be made - hence, the award might not be made in some years.

The award would consist of a certificate and modest sum of money or other token (details to be agreed), which would be presented by the nominator (or by the EB) during the next AGM. Here, the awardee would have the opportunity to give a short presentation on the work for which he or she received the award.

Although it seemed that this would be a good initiative to pursue, it was felt that the Fellowship Programme should take priority. Once again, if and when this were to go ahead, a range of new Web pages would need to be set up (to promote the call for nominations and to announce the winner); details of the award itself would also need to be confirmed prior to launching the initiative. 
New proposals, affiliations, collaborations

In previous meetings, time has been set aside to reflect on the future of EMBnet, and the impact of globalisation on our formerly European organisation. This year was no exception. Although, originally, we were to have had a structured session at this point on the agenda, the rather unusual circumstances at the hotel obliged us to convene in the bar. In this 'relaxed' setting, we discussed the relationships between members of EMBnet and projects such as SeqAhead and AllBio, and with organisations like GOBLET and ISCB. There was a general sense that it would be advantageous for EMBnet to focus at least part of its future work around a common theme or project, which would allow us to seek funding in a more inclusive way (experience has shown that relying exclusively on European funds can be divisive in a global organisation). Given that members of EMBnet have very different research interests, it was considered unlikely that a common project could be identified; however, it was recognised that education and training (including sharing bioinformatics knowledge, bioinformatics capacity building, disseminating best practices, curriculum development, etc.) was a theme that cuts across all research niches.

This conclusion resonated strongly with the outcome of the survey conducted earlier in the year by the P\&PR PC, which found that amongst the principal core values of EMBnet are bioinformatics education/training, networking and capacity building. This naturally led to a discussion focused around the development of bioinformatics curricula and train-the-trainer programmes, and recognition that these are currently "hot topics' in countries across the world (e.g., initiatives are currently being driven by the $\mathrm{H} 3 \mathrm{ABioNe}^{6}$ bioinformatics curriculum degree development task-force, the ISCB bioinformatics curriculum development task-force, the GOBLET Learning, Education and Training Committee, and ELIXIRUK). To capitalise on this momentum, and to draw from the combined experiences of members of EMBnet, GOBLET, SeqAhead and AllBio in particular, it was agreed to organise a meeting to discuss development of global bioinformatics MSc curricula (ideally, in late September 2014, alongside the final AllBio AGM). Results from

6 h3abionet.org this meeting, if co-funded and co-organised, could be considered a joint outcome of AllBio and EMBnet, ultimately to be taken forward by EMBnet/GOBLET after the end of AllBio.

\section{Summary of outcomes and actions}

Discussions amongst the participants of the workshop and AGM (see Figure 6) were wide-ranging and remarkably productive. Several outcomes and actions were agreed, as follows:

i) each Committee Chair and the EB should review their structure and membership, to delegate tasks and/or to recruit new members as appropriate, to update the website accordingly, to meet regularly and to deliver, and subsequently report on, tangible outcomes;

ii) to take the Fellowship Programme forward: the EB will need to develop the details and circulate documentation to all - together with the TMPC, a page will need be set up on the website to publish the new programme, which would need to be advertised/promoted with the support of the P\&PR PC;

iii) the $E B$ should formulate the details of a Service Award scheme, but should progress this only after the Fellowship Programme has been established;

iv) to organise a meeting, late September 2014, ideally alongside the final AllBio AGM, to discuss development of global bioinformatics MSc curricula (the results could be considered a joint outcome of AllBio and EMBnet);

v) to target and invite Linkedln EMBnet group members to become EMBnet members, using the Fellowship Programme as an incentive, once this has been properly launched;

vi) as part of i), ii) and v), Committee Chairs should publish on the website their current working programs and their future projects, not just to showcase their work, but also to provide potential focal points for Fellowship applications; and

vii) the E\&T PC should help to develop both a core for future tutorial programmes, and a set of ground rules for running and hosting these events (including aspects such as the capacity of the room - e.g., max. $\sim 30$ participants - availability of desktops, trouble-shooting the local infrastructure in advance, inviting guest speakers, placing the event closer to the AGM, etc.); ultimately, to develop an expanded tutorial, of up to two days, 


\section{\begin{tabular}{lll}
\hline G786 & BEPOBTS & EMBnet.journal20
\end{tabular}}

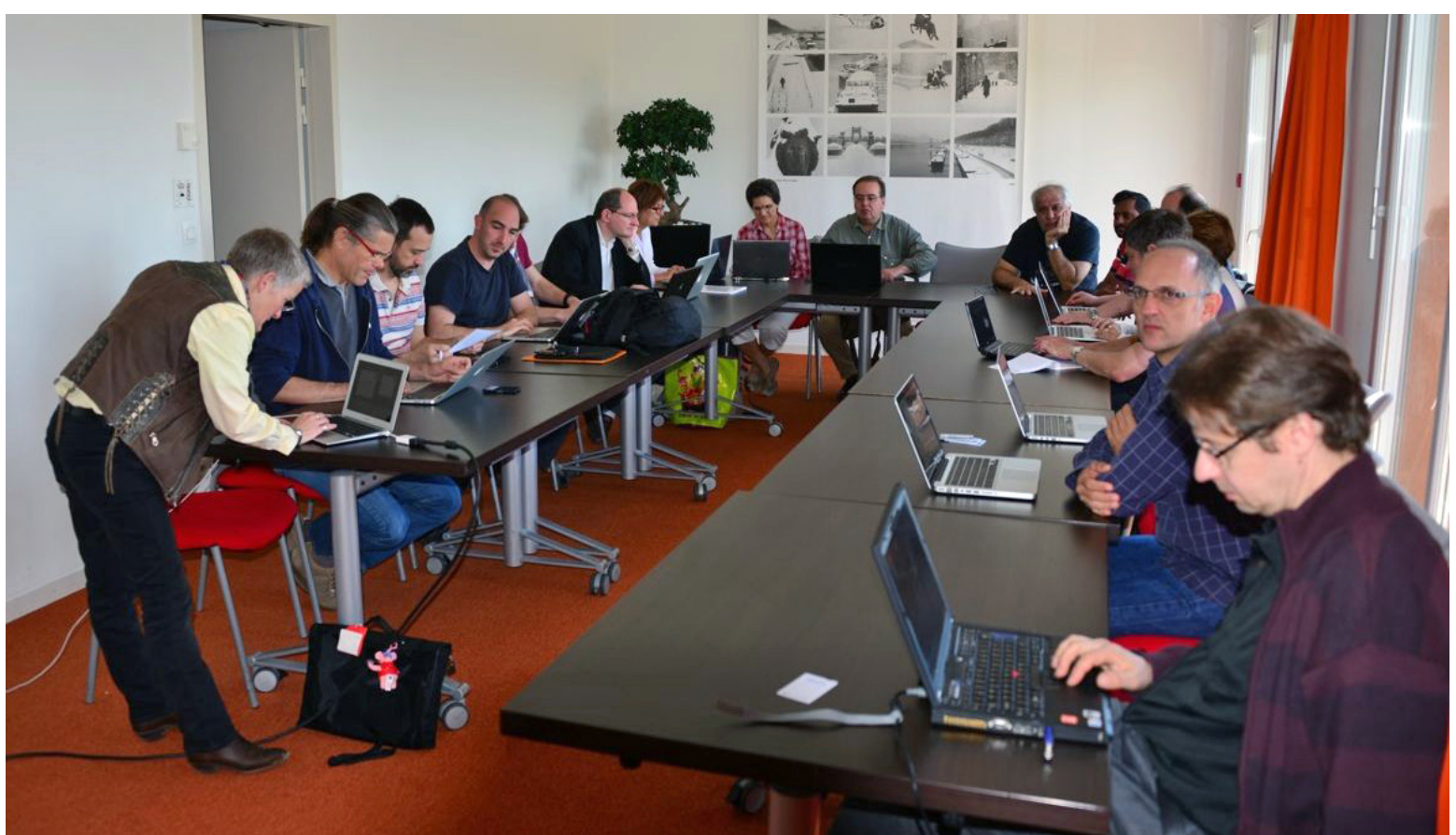

Figure 6. Setting up for business, AGM 2014.

with a small fee so that the event covers its costs, or better, brings income to EMBnet.

\section{Conclusion}

It's clear that there are many opportunities ahead for EMBnet, and this meeting provided a timely opportunity to outline plans for taking some of these forward. During the 2014 meeting, we were fortunate to be able to celebrate the arrival of our latest individual member, Axel Thieffry, whom we hope will be willing to take an active role in helping us to drive some of these new plans forward, and especially to help inspire and recruit more eager and talented individual members like himself!

As always, there's still a lot more work to do. We therefore encourage you all to contribute your energies and visions to EMBnet, to ensure EMBnet's continued success as the Global Bioinformatics Network!

\section{Acknowledgements}

We are grateful to Guy Perriere for his work in organising these events, and especially for medi- ating with the hotel management to secure a new meeting room under rather unusual (not to mention, stressful) circumstances! This year, we would also again like to thank Domenica D'Elia for her energy and fortitude in coordinating and sustaining the many successful activities of the P\&PR PC; Rafael Jimenez for his ongoing technical support of the website; and Lubos Klucar for his patient and consistent work in managing the production of EMBnet.journal.

\section{T.K.Attwood}

On behalf of the Executive Board

\section{References}

Schneider MV, Watson J, Attwood TK, Rother K, Budd A et al. (2010) Bioinformatics training: a review of challenges, actions and support requirements. Brief. Bioinform. 11(6), 544-551. http://dx.doi. org/10.1093/bib/bba021.

Via A, Blicher T, Bongcam-Rudloff E, Brazas MD, Brooksbank $\mathrm{C}$ et al. (2013) Best Practices in Bioinformatics Training for Life Scientists. Brief. Bioinform. 14(5), 528-537. http:///dx. doị. org/10.1093/bib/bbt043

Via A, De Las Rivas J, Attwood TK, Landsman D, Brazas MD et al. (2011) Ten simple rules for developing a short bioinformatics training course. PLoS Comput. Biol. 7, el002245. http://dx.doi.org/10.1371/journal.pcbi.1002245 